\title{
Factors Influencing Cavitation Erosion of NiCrSiB Hardfacings Deposited by Oxy-Acetylene Powder Welding on Grey Cast Iron
}

\author{
Mirosław Szala ${ }^{1 *}$, Mariusz Walczak' ${ }^{1}$ Tadeusz Hejwowski ${ }^{1}$ \\ 1 Department of Materials Engineering, Faculty of Mechanical Engineering, Lublin University of Technology, \\ Nadbystrzycka 36D, Lublin 20-618, Poland \\ * Corresponding author's email: m.szala@pollub.pl
}

\begin{abstract}
The study presents the results of cavitation erosion $(\mathrm{CE})$ resistance of two $\mathrm{NiCrSiB}$ self-fluxing powders deposited by oxy-acetylene powder welding on cast iron substrate grade EN-GJL-200. The mean hardness of deposits A$\mathrm{NiCrSiB}, \mathrm{C}-\mathrm{NiCrSiB}$ is equal to $908 \mathrm{HV}, 399 \mathrm{HV}$ and exceeds those of EN-GJL-200 and X5CrNi18-10 reference specimens $197 \mathrm{HV}$ and $209 \mathrm{HV}$, respectively. To study CE, the vibratory apparatus has been used and tests were conducted according to the ASTM G32 standard. Cavitation eroded surfaces were examined using a profilometer, optical and scanning electron microscopy. The research indicated that the $\mathrm{CE}$ resistance, expressed by the cumulative mass loss decreased in the following order $\mathrm{C}-\mathrm{NiCrSiB}>\mathrm{A}-\mathrm{NiCrSiB}>\mathrm{X} 5 \mathrm{CrNi1}$-10 $>$ EN-GJL-200. Therefore, hardfacings were characterised by lower cumulative mass loss, in turn, higher CE resistance than the reference sample and therefore they may be applied as layers to increase resistance to cavitation of cast iron machine components. Results indicate that in the case of multiphase materials, hardness cannot be the main indicator for $\mathrm{CE}$ damage prediction while it strongly depends on the initial material microstructure. To qualitatively estimate the cavitation erosion damage $\left(\mathrm{CE}_{\mathrm{d}}\right)$ of $\mathrm{NiCrSiB}$ self-fluxing alloys at a specific test time, the following factors should be considered: material microstructure, physical and mechanical properties as well as surface morphology and material loss both estimated at specific exposure time. A general formula for the $\mathrm{CE}_{\mathrm{d}}$ prediction of $\mathrm{NiCrSiB}$ deposits was proposed.
\end{abstract}

Keywords: surface engineering, $\mathrm{NiCrSiB}$, cavitation erosion, hardness, powder welding, stainless steel, cast iron, hardfacing, surface roughness

\section{INTRODUCTION}

Cast iron still is one of the most popular materials applied for the manufacturing of cast components for fluid machinery. It is known that pump casings, valves parts and impellers are prone to deterioration due to not only wear, corrosion, slurry- and/or solid-particle erosion but also can be deteriorated by cavitation erosion [1-3]. From the mentioned above wear processes the cavitation erosion (CE) has an overly complex nature. Overall, the CE phenomenon is described as a material degradation process relying on harmful fluid action initiated by pressure fluctuations in the liquid. When the liquid pressure drops, the vapour can grow, and as the pressure increases, the vapour bubbles implode. The resulting emission of shock waves and liquid-jet cause degradation of a solid material [4]. Though the CE damage mechanism has primally mechanical nature, it can be intensified by the working fluid corrosive environment, presence of solid-particle, elevated temperature action alone or synergistic interactions between mentioned above deterioration processes [5-7]. Unfortunately according to the literature of the subject [8$10]$, cast iron has relatively low CE resistance. On the contrary stellites (cobalt-based alloys) [11], stainless steels [12], aluminium bronzes [13] or shape memory alloys [14] present an elevated resistance to $\mathrm{CE}$. 
Worn ferrous machine components, depending on the cost analysis are replaced by new parts or regenerated. Thus the broad range of surface engineering techniques likewise induction hardening [15], thermal spraying [16,17], conventional overlay welding and cladding $[18,19]$, wet (underwater) welding $[20,21]$ or surface alloying $[22,23]$ are utilised. Literature reports that the most typical materials for regenerating or prolonging thw operation time of cast iron machine parts are polymers [24,25], metal alloys [26,27] or different composites [28,29]. From the broad grades of metallic materials, the nickel alloys present promising applicability to cast iron workpieces [26]. The self-fluxing nickel alloys Ni-B$\mathrm{Si}$ and Ni-Cr-B-Si can be deposited by different methods likewise oxy-acetylene powder welding [30], plasma arc welding [26,31], laser cladding [32], flame spraying [33,34], HVOF [35,36]. The low melting point and high substrate wettability guarantee effective deposition of $\mathrm{NiCrSiB}$ on different metallic substrates likewise steel [37], Ti6A14V titanium alloy and cast iron [26,34].

The self-fluxing nickel alloys have a complex microstructure dominated by nickel-based solid solution, eutectics e.g. $\mathrm{Ni}_{3} \mathrm{~B}, \mathrm{Ni}_{5} \mathrm{Si}_{2}$, chromium carbides mainly $\mathrm{Cr}_{23} \mathrm{C}_{6}$ and $\mathrm{Cr}_{7} \mathrm{C}_{3}$, borides or complex chromium carboborides $[30,35,38]$. Furthermore, usually deposits hardness increases as the content of chromium, boron, silicon and carbon [38]. Thus the field of application of nickel-based self-fluxing alloys includes mainly fabrication of wear-resistant coatings operated in metallurgic, mining and oil-extracting, energy, glass and chemical equipment, stamping and pressing equipment, automotive and boat parts, gas-pumping devices, agricultural technology, etc [39]. Thanks to the microstructure and mechanical properties nickel-based self-fluxing alloys present promising behaviour in the corrosive environment [34], in sliding wear applications [40], at high-temperature applications (especially with Mo addition) [41,42]. However, unfortunately, $\mathrm{NiCrSiB}$ self-fluxing alloys $\mathrm{CE}$ resistance is not completely presented by the professional literature. Generally, the reports on CE behaviour of NiCrSiB-based deposits are scant and the diversity of deposition methods makes it difficult to classify their CE resistance. Exemplary the Wang et al. [43] report on poor resistance to cavitation of YSZ-NiCrSiB composite coatings fabricated by atmospheric plasma spraying.
Furthermore, Kekes et al. [36] report that CE material loss of HVOF WC-Co/Cr - NiCrFeB$\mathrm{SiC}$ coatings are decelerated by the increase of nickel-based metallic phase and pure metallic coating i.e. NiCrSiB-type has superior $\mathrm{CE}$ resistance than WC-CoCr cermet. Similarly Wu et al. [44] report on higher CE resistance of nickel-based self-fluxing alloy than AISI 304 stainless steel, which agrees with the results given in our previous study [45]. Therefore, due to the diversity of the chemical composition of nickel self-fluxing alloys and a variety of deposition methods, there is a demand to investigate the $\mathrm{CE}$ behaviour of $\mathrm{NiCrSiB}$ deposits. Especially oxy-flame powder welding seems promising to prevent and regenerate the cast iron components operated in a $\mathrm{CE}$ environment. Moreover, to fully understand the $\mathrm{CE}$ mechanism of metallic materials, the relationship between microstructure, hardness and surface roughness damage must be analysed.

This paper aims to investigate the factors influencing the $\mathrm{CE}$ behaviour of the $\mathrm{NiCrSiB}$ oxyacetylene powder welds. The analysis was conducted concerning the reference structural materials i.e. grey cast iron (EN-GJL-200) and stainless steel (X5CrNi18-10).

\section{MATERIALS AND METHODS}

The NiCrSiB hardfacings were deposited using the oxyacetylene torch dedicated to powder welding. The workpiece (grey cast iron grade EN-GJL-200) was heated with the torch, then the powder was introduced into the gas stream from the integral powder hopper and transferred to the workpiece through the flame to obtain 3-4 mm thick hardfacings. Two different commercial Kennametal Stellite feedstock powders were used, see Table 1. Therefore, deposits differ in chemical composition, hardness and microstructure. The microstructure of $\mathrm{NiCrSiB}$ hardfacings was studied in polished metallographic specimens using a scanning electron microscope (SEM). Weld deposits hardness was measured using Future-Tech FM800 according to ISO 6507 standard and at the latest fifteen indentations were made to achieve statistical accuracy. Prior cavitation erosion (CE) testing specimens were machined to obtain dimensions of $\varnothing 25 \times 10 \mathrm{~mm}$ and roughness of $\mathrm{S}_{\mathrm{a}}<0.06$ $\mu \mathrm{m}$ and $\mathrm{S}_{\mathrm{z}}<0.72 \mu \mathrm{m}$. CE investigations were 
conducted in compliance with the ASTM G32 standard through a vibratory cavitation apparatus using the stationary specimen method [46]. The schematic drawing of the test rig is shown in Figure 1. To perform the tests, the polished specimen surface was positioned $1 \pm 0.05 \mathrm{~mm}$ from the horn tip in a cooling bath filled with distilled water maintained at $25 \pm 2{ }^{\circ} \mathrm{C}$. Total test time equals six hours. Specimens were weighed with an accuracy of $0.1 \mathrm{mg}$ to measure the mass loss as a function of the cavitation time. The CE characterisation was carried out for two grades $\mathrm{NiCrSiB}$ powder-weld deposits (see Table 1) and two reference materials namely cast iron grade EN-GJL-200 (parent metal) and stainless steel grade $\mathrm{X} 5 \mathrm{CrNi} 18-10$, AISI 304 (popular reference material used in CE testing). During the selected $\mathrm{CE}$ test time intervals damaged surfaces were characterised using the scanning electron microscope and stereoscope optical microscope Nikon SMZ 1500. To better understand the $\mathrm{CE}$ behaviour of $\mathrm{NiCrSiB}$ hardfacings, eroded surfaces were investigated using Hommel-Etamic 3D T8000 RC120-400 profiler therefore 3D surface morphology and 2D roughness profiles were measured according to ISO 25178 and ISO 4287 standards.

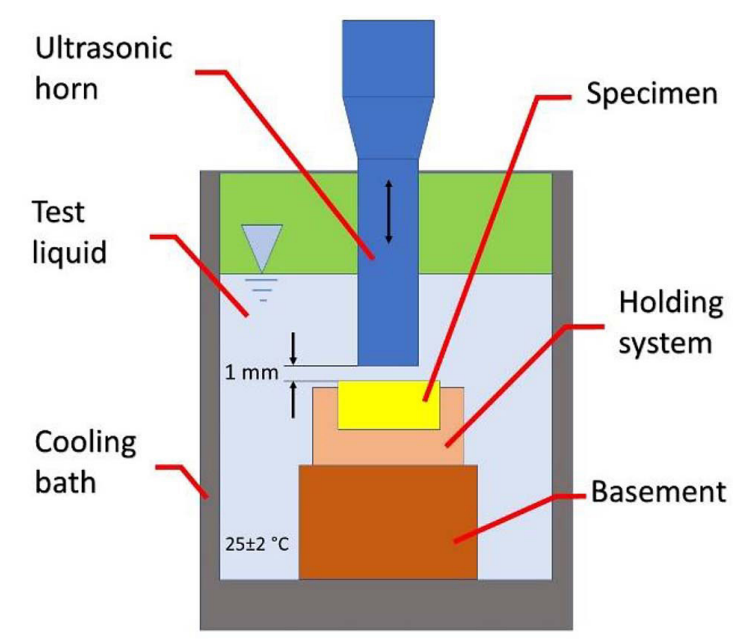

Fig. 1. Schematic representation of the ultrasonic vibratory system used for cavitation (stationary specimen configuration)

\section{RESULTS AND DISCUSSION}

Based on the analysis of metallographic investigations done using SEM and analysis of the cavitation erosion (CE) curves followed by the profilometric measurements allow confirming the effect of microstructure on the CE process. First of all, the microscopic investigation supports the literature data information regarding the microstructure of the coating [30,48]. Oxy-acetylene deposits microstructures consist of a relatively ductile Ni-based matrix with various amounts of hard particles (Fig. 2). Sample A-NiCrSiB contains much more percentage of hard phases than the $\mathrm{C}-\mathrm{NiCrSiB}$ sample (Table 1), which directly derives from the chemical composition of feedstock powders. It is known that chromium, boron, carbon favours the creation of hard phases, therefore, the microstructure of $\mathrm{C}-\mathrm{NiCrSiB}$ contains fewer hard phases but is mainly strengthened by the predominant hard phase which is $\mathrm{Ni}_{3} \mathrm{~B}$ [38]. Moreover, in the case of sample A-NiCrSiB, hard particles are present in a form of agglomerates and particle clusters. Both hardfacings characterise the minimal presence of pores. The microstructure strongly influences the mean hardness and wide scatter of hardness, visible in Figure 3. The mean hardness of A-NiCrSiB coating (908 HV0.05) exceeds two times those reported for C$\mathrm{NiCrSiB}$ (399HV0.05) which, in turn, is harder than reference specimens made of cast iron (197 HV30) and stainless steel (209 HV30). Due to its homogenous austenitic microstructure, stainless steel reports a reduced spread of hardness results, even tested under different loads [49,50]. Hardfacings have a much more complex microstructure containing different rations of hard to soft phases which increases the spread of hardness measurements.

Both hardness and microstructure are crucial for the wear performance of metallic materials. Analysis of the eroded surfaces (Fig. 5) and CE curves (Fig. 4) indicates that soft cast iron definitively has inferior CE resistance. Mass loss of cast iron is more than 10-times higher than

Table 1. Nominal chemical composition of feedstock powders and hardness oxy-acetylene powder welds according to manufacturer data [47]

\begin{tabular}{|c|c|c|c|c|c|c|c|c|}
\hline \multirow{2}{*}{ Specimen code } & \multicolumn{7}{|c|}{ Chemical composition, wt\% } & \multirow{2}{*}{ Hardness, HRC } \\
\cline { 2 - 10 } & $\mathrm{Cr}$ & $\mathrm{B}$ & $\mathrm{Si}$ & $\mathrm{C}$ & $\mathrm{Fe}$ & Other & $\mathrm{Ni}$ & B \\
\hline A-NiCrSiB & 17.0 & 3.6 & 4.5 & 0.6 & 3.0 & $\begin{array}{c}\text { Cu 2.5; } \\
\text { Mo 2.5 }\end{array}$ & Bal. & $53-63$ \\
\hline C-NiCrSiB & 7.5 & 1.7 & 3.5 & 0.25 & 2.5 & - & Bal. & $38-45$ \\
\hline
\end{tabular}


a)

b)

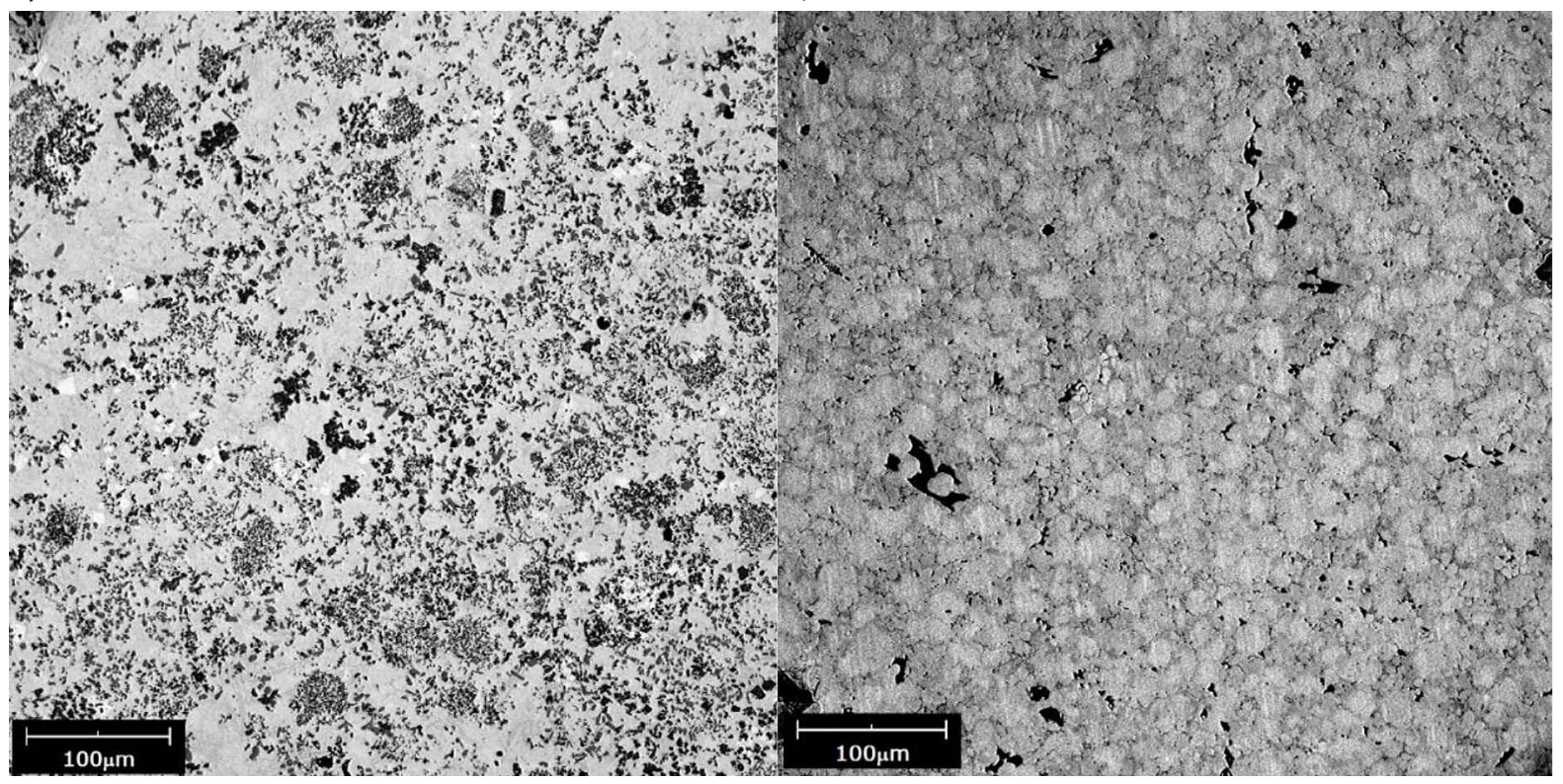

Fig. 2. Microstructure of the nickel-based hardfacings: a) A-NiCrSiB; b) C-NiCrSiB

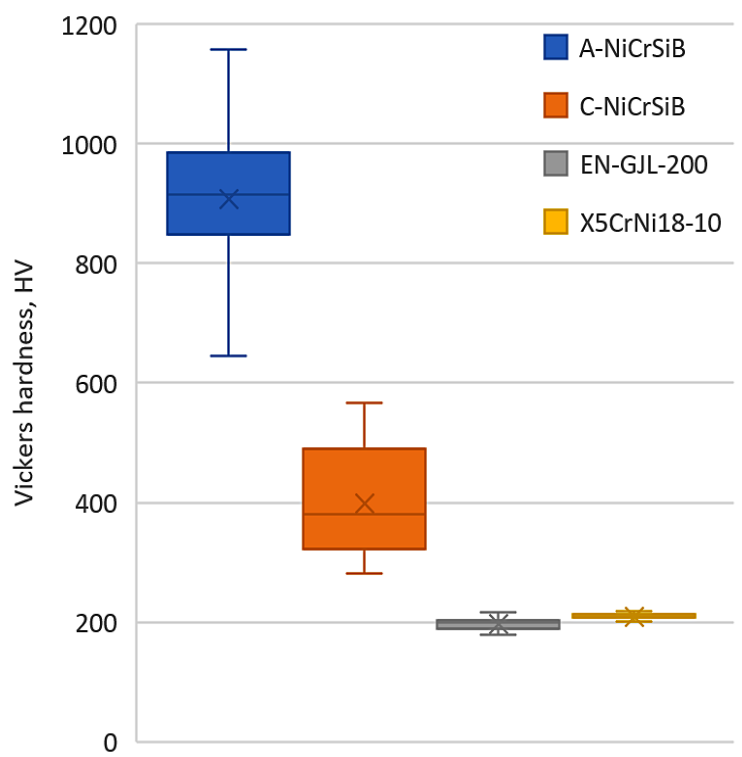

Fig. 3. The hardness of $\mathrm{NiCrSiB}$ hardfacings (HV0.05) and reference cast iron and stainless steel (HV30)

NiCrSiB hardfacings and $\mathrm{X} 5 \mathrm{CrNi18}$-10 specimens. Therefore, oxy-acetylene powder welds positively prevent the cast iron substrate from erosive loss. Moreover, erosion resistance of $\mathrm{NiCrSiB}$ deposits exceeds those reported for $\mathrm{X} 5 \mathrm{CrNi18-10}$ reference specimen (taking into account the cumulative mass loss after $6 \mathrm{~h}$ ). On the other hand, in the case of the NiCrSiB hardfacings, A-NiCrSiB presents higher mass loss than softer $\mathrm{C}-\mathrm{NiCrSiB}$. This derives from the properties of investigated materials that affect CE behaviour.

Figures 5 and 6 show the differences in eroded surfaces morphologies. Comparative analysis of the hardness and time-dependent erosion mass loss confirms the general influence of microstructure and hardness on cumulative erosion mass loss. It is known, that the CE process of metallic materials can be divided into four main stages [4,51]: incubation, acceleration, deceleration and terminal periods which are read from the cavitation curves. The analysis of CE plots confirms high mass loss of cast iron at $6 \mathrm{~h}$ and presence of acceleration, deceleration and terminal CE phases (incubation period is negligible), see Fig. 4. Cast iron microstructure contains the ferritic-perlitic matrix and soft graphite flakes. Optical microscope investigations are well visualised (Fig. 5) much severe surface pitting for cast iron than for other tested materials. SEM observations confirm that erosion is initiated by the removal of the graphite phase (Fig. 6a) which follows observations of Chmiel et al and Kim et al. [52,53]. This opens access for cavitation action to aggressively penetrate the metallic matrix. This result in erosion acceleration by detaching the ferrous matrix, which is well visualised in Figure 6a.

On the other hand, stainless steel has a clear incubation period of up to $1 \mathrm{~h}$ of exposure, see Figure 4. At this stage, due to the accumulated internal stresses across the surface layers, plastic deformation initiated and the material surface 

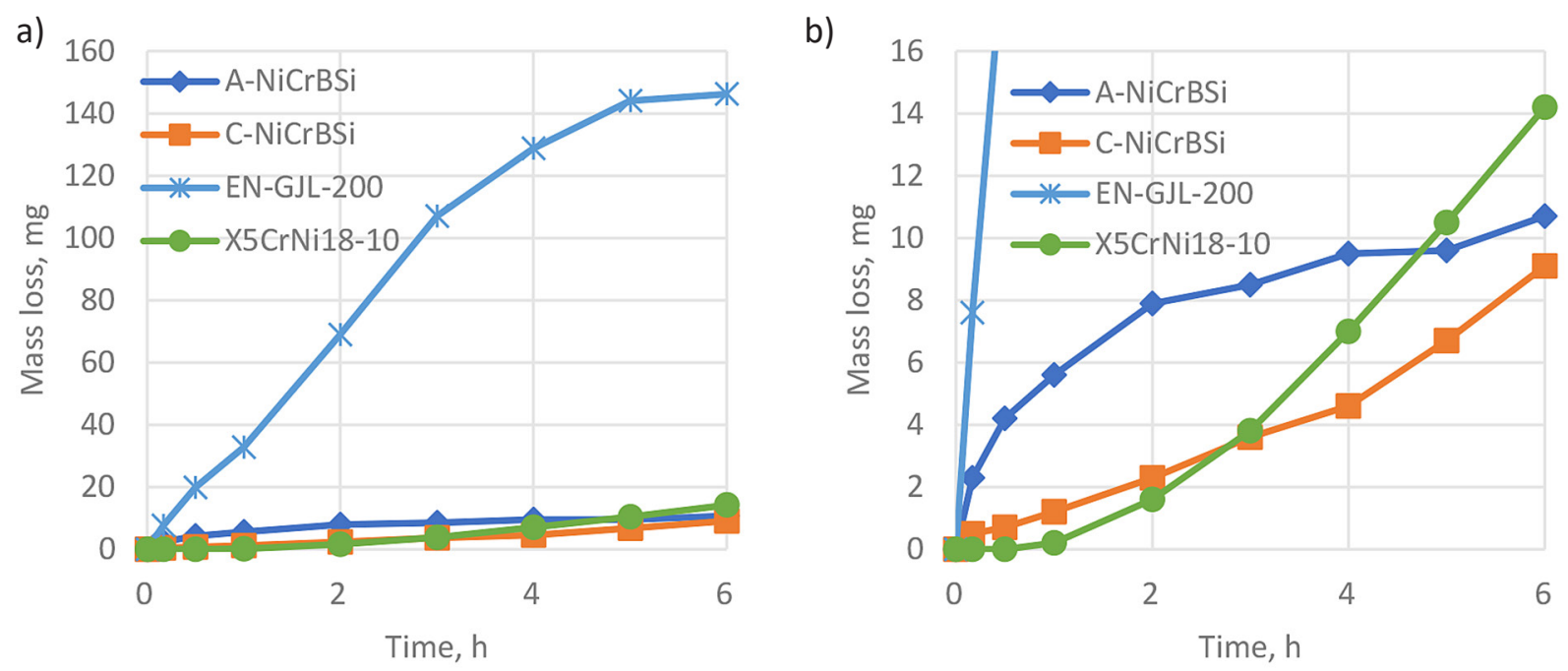

Fig 4. Cumulative mass loss of investigated specimens (a); (b) - an enlarged area of the plot given in (a)

a)

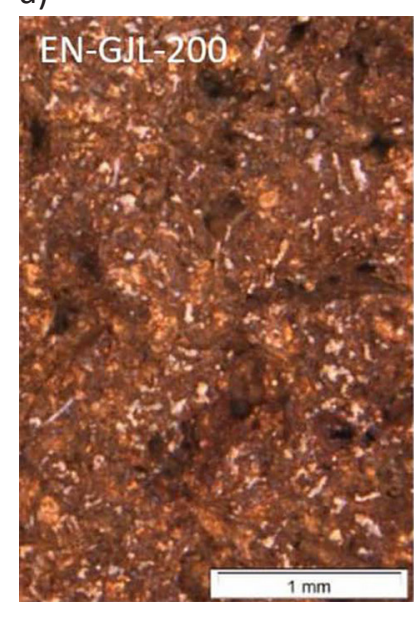

b)

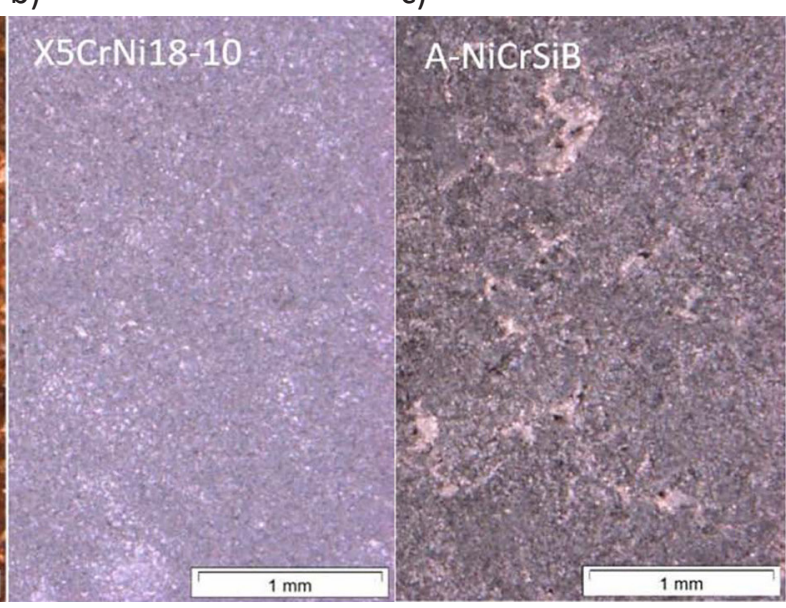

d)

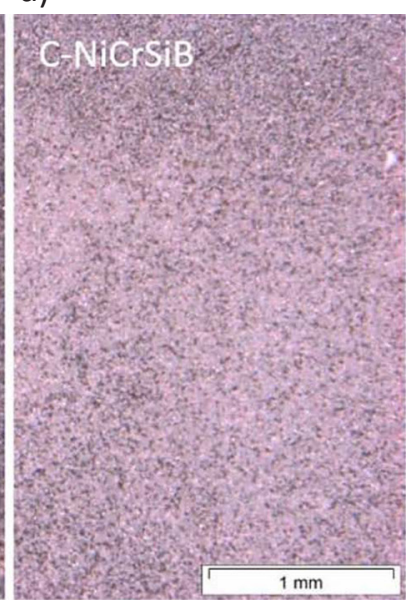

Fig 5. Comparison of eroded surfaces after $6 \mathrm{~h}$ of testing: a) EN-GJL-200; b) X5CrNi18-10; c)A-NiCrSiB; d) C-NiCrSiB

started to deform (work hardening) [54]. Following this incubation period, the acceleration state of erosion can be read. Stainless steel grade X5CrNi18-10 has a microstructure dominated by austenite. Microscopic analysis indicates that severe plastic deformation of surface, visible twinning and detachment of fatigue deformed surface material (Fig. 6b). These results are similar to findings reported for $\mathrm{CE}$ behaviour stainless steel $[55,56]$.

$\mathrm{NiCrSiB}$ self-fluxing deposits erosion behaviour differs from those presented for reference materials. The initial states of $\mathrm{CE}$ of $\mathrm{A}-\mathrm{NiCrSiB}$ present accelerated mass loss which refers to hard particle and agglomerate clusters detachment taking place due to their poor cohesion (Fig. 6c). However, after $2 \mathrm{~h}$ of testing the erosion rate decreases. At further stages of erosion, the mass-loss rate slows down, and it seems that the hard matrix effectively withstands the cavitation loads. The final mass loss noted at $6 \mathrm{~h}$ of testing, is comparable to C-NiCrSiB. Nevertheless, $\mathrm{C}-\mathrm{NiCrSiB}$ sample $\mathrm{CE}$ behaviour presents advanced plastic deformation at the initial stages of erosion (Fig. 6d). Less rich in hard phases structure of $\mathrm{C}-\mathrm{NiCrSiB}$ successfully mitigates the material loss by absorbing the CE load due to surface deformation. Further, the mass-loss rate increases (Fig. 4) while the fatigue-deformed material is detached. Therefore, even the initially sample $\mathrm{C}-\mathrm{NiCrSiB}$ has lower materials loss than A-NiCrSiB, after $6 \mathrm{~h}$ of exposure their cumulative mass losses are at a comparable level.

The microstructure of metallic materials plays a crucial role in the time-dependent erosion behaviour of metallic materials. Even the high differences in the hardness of nickel deposits and reference materials, both cast iron and $\mathrm{A}-\mathrm{CrNiSiB}$ 
a)
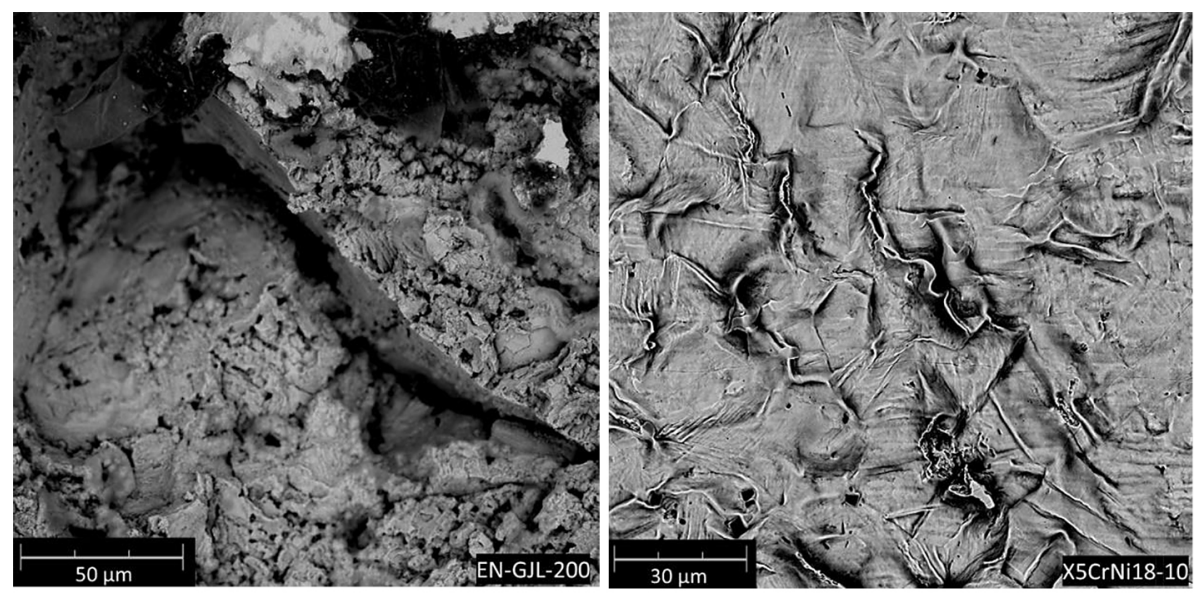

c)

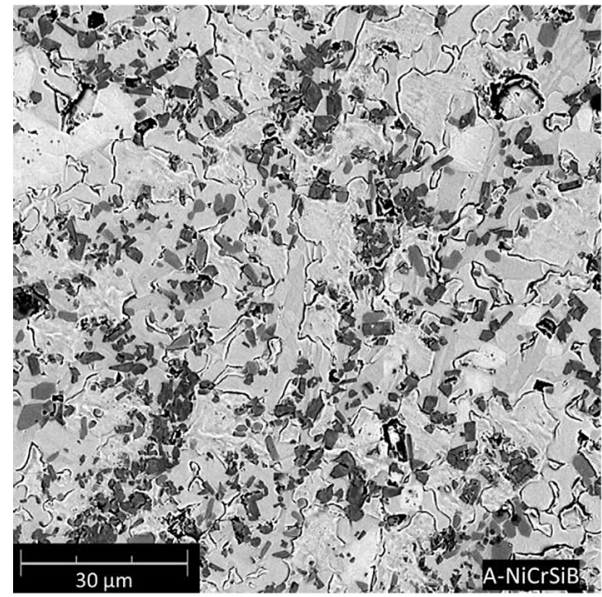

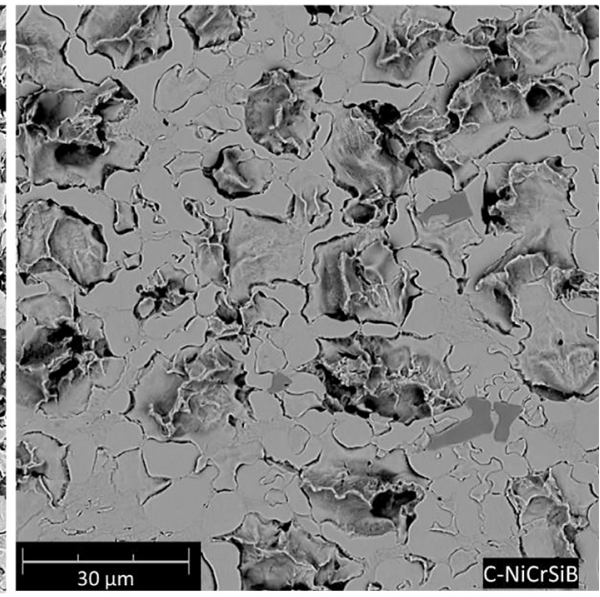

Fig. 6. Cavitation damaged surfaces after $2 \mathrm{~h}$ of exposure:

a) EN-GJL-200; b) X5CrNi18-10; c) A-NiCrSiB; d) C-NiCrSiB

as well as stainless steel and $\mathrm{C}-\mathrm{NiCrSiB}$ presents comparable to each other characteristics of $\mathrm{CE}$ erosion wear behaviours. Of course, the rate of CE failure, and differs and it seems that it is controlled by material properties, likewise hardness. The operation performance of the machine components strongly correlates with the surface roughness. Therefore many authors consider the surface roughness as a crucial indicator of metallic surface industrial usability [57-59]. The same as for many other deterioration processes, the rate of CE damage can be evaluated by surface roughness development analysis. This was described in our previous papers on plastics [24], composites [55], coatings [60] and metallic materials [11]. Therefore, in the case of the powder welded $\mathrm{NiCrSiB}$ alloys the $\mathrm{CE}$ damage was evaluated by profilometric measurements. The analysis of the results given in Figs. 7 and 8, allows to state that eroded surfaces morphology and roughness parameters supplement the erosion behaviour. Specimens that have much complex microstructure (likewise $\mathrm{A}-\mathrm{NiCrSiB}$ and cast iron) presents higher $\mathrm{S}_{\mathrm{z}}$ and lower $\mathrm{S}_{\mathrm{a}}$ roughness parameters than specimens that have much homogenous microstructure (likewise $\mathrm{C}-\mathrm{NiCrSiB}$ and stainless steel). Selective phase detachment and low surface deformation result in the growth of deeper pits observed for $\mathrm{A}-\mathrm{NiCrSiB}$ while in the case of $\mathrm{C}-\mathrm{NiCrSiB}$ specimen the relatively soft matrix undergoes relatively uniform surface deformation and lesser pitting (Fig. 7). It seems that the ratio of $S_{a}$ to $S_{z}$ parameters measured at specific exposure time could be used for the characterisation of cavitation damage too.

The literature presents different attempts for estimating CE resistance of material systems [54,61-63]. However, there is no formula reported for $\mathrm{NiCrSiB}$ self-fluxing deposits. Therefore, the analysis of the results presented in the current study allows proposing the qualitative relationship for estimating the cavitation erosion damage $\left(\mathrm{CE}_{\mathrm{d}}\right)$ of a selected group of metallic materials, estimated at a specific exposure time, given by formula (1).

$$
\mathrm{CE}_{\mathrm{d}}(t)=f(\mathrm{~S}, \mathrm{~L}, \mathrm{M}, \mathrm{P})
$$


where: material microstructure $(\mathrm{M})$ - characterised by a number of phases, structure refinement and homogeneity, phase morphology, porosity, chemical composition, etc; physical and mechanical properties $(\mathrm{P})$ - described by hardness, Young modulus, plasticity, toughness, cohesion, thermal conductivity, corrosivity etc; surface morphology at specific test time (S) characterised by surface roughness, nonuniformities, surface development rate etc; material loss (L) evaluated at specific cavitation exposure time - mass loss, erosion rate, volume loss etc.

The proposed $\mathrm{CE}_{\mathrm{d}}$ qualitative relationship combines main input factors such as $\mathrm{M}$ and $\mathrm{P}$ combined with the indicators evaluated at specific exposure time, namely S and L. Of course, to select the scalar value $\mathrm{CE}_{\mathrm{d}}$ must be verified by broader studies done for a range of $\mathrm{NiCrSiB}$ deposits. Generally, hardness is considered as a predominant factor used for the estimation of CE resistance of materials. However, this study shows that the ratio of cavitation erosion loss depends on both microstructure and hardness and these factors should be considered together. It seems that in the case of complex-microstructure materials, likewise $\mathrm{NiCrSiB}$ alloys, $\mathrm{CE}_{\mathrm{d}}$ depends strongly on microstructure uniformity. Furthermore, to forecast the CE failure of specific materials, their in-process behaviour should be taken into account. Thus, not only mass loss but also a)

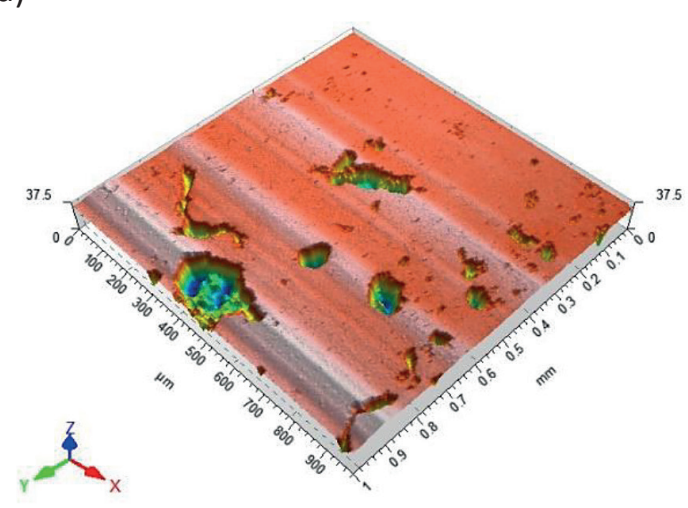

b)

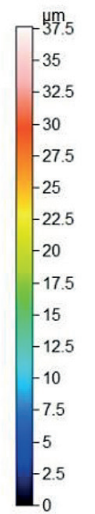

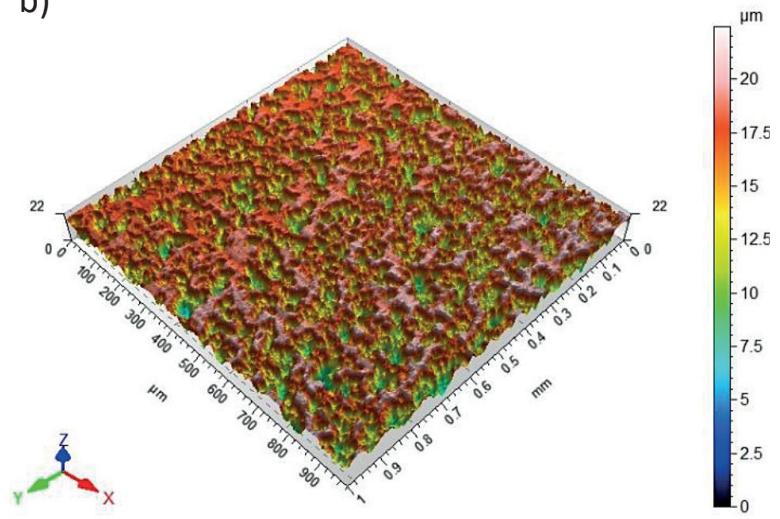
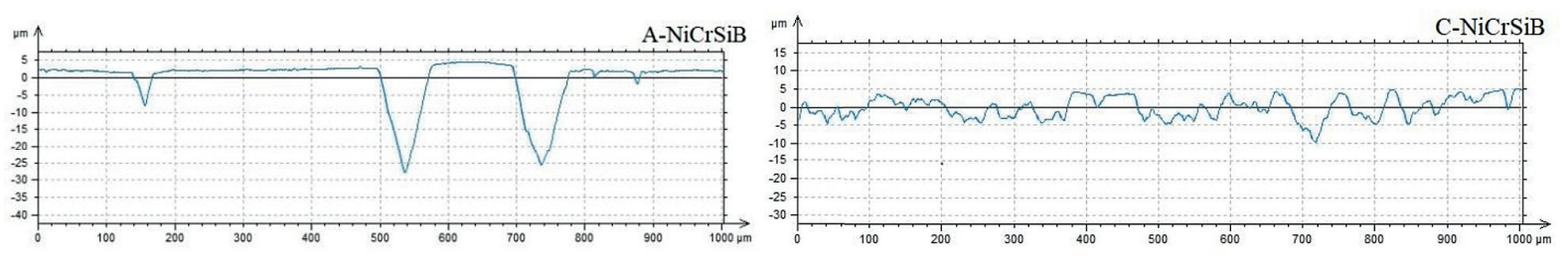

Fig. 7. Surface morphology of $\mathrm{NiCrSiB}$ powder-welds measured after $6 \mathrm{~h}$ of exposure to cavitation erosion: a) $\mathrm{A}-\mathrm{NiCrSiB}$ and b) $\mathrm{C}-\mathrm{NiCrSiB}$

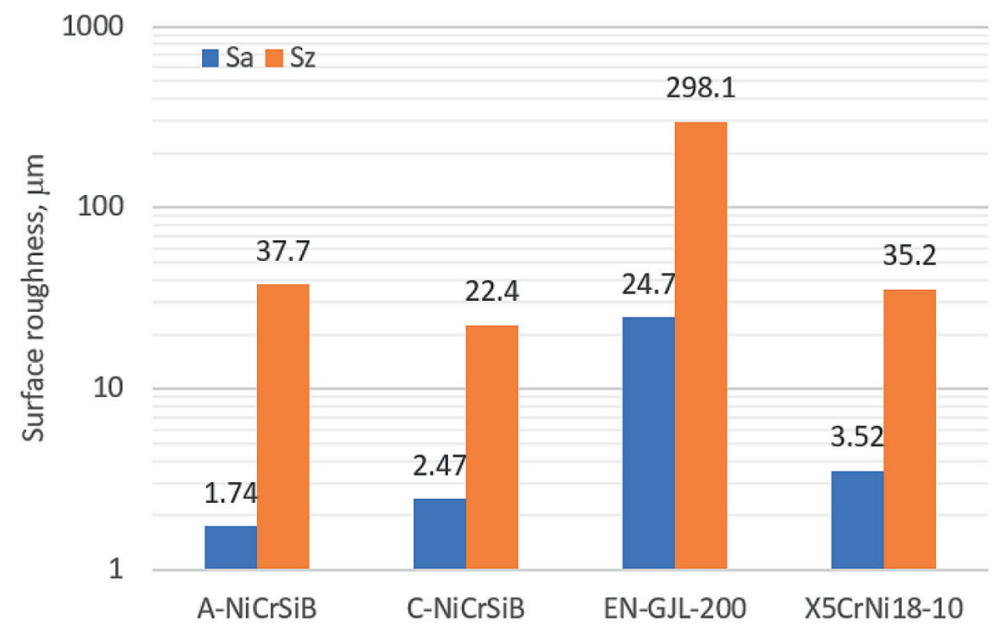

Fig. 8. Surface $S_{a}$ and $S_{z}$ roughness of damaged surfaces after 6 h of cavitation (logarithmic scale of Y-axis) 
the development of surface morphology should be included. Of course, each of the factors given in a proposed $\mathrm{CE}_{\mathrm{d}}$ relationship should be selected with care and the formula will be validated for the set of self-fluxing $\mathrm{NiCrSiB}$ hardfacings.

\section{CONCLUSIONS}

The goal of the study was to investigate the factors influencing the cavitation erosion (CE) behaviour of the $\mathrm{NiCrSiB}$ hardfacings deposited by oxy-acetylene powder welding on cast iron. The analysis was conducted in relation to the reference structural materials i.e. cast iron and stainless steel. The results of the study lead to the following conclusions:

1. The microstructure of oxy-acetylene powder weld $\mathrm{NiCrSiB}$ hardfacings consists of nickel matrix, eutectics and hard phases. This influences the hardness and $\mathrm{CE}$ behaviour of deposits. The mean hardness of A-NiCrSiB, C-NiCrSiB, EN-GJL-200 and X5CrNi18-10 were $908 \mathrm{HV}$, $399 \mathrm{HV}, 197 \mathrm{HV}$ and $209 \mathrm{HV}$, respectively.

2 . The research indicated that the cavitation erosion (CE) resistance, expressed by the cumulative mass loss after $6 \mathrm{~h}$ of testing, decreased with the following order $\mathrm{C}-\mathrm{NiCrSiB}>\mathrm{A}-\mathrm{NiCrSiB}$ $>$ X5CrNi18-10 > EN-GJL-200. Therefore, oxy-acetylene powder-welds deposited on cast iron successfully prevent it from erosive deterioration.

3. The microstructure of $\mathrm{NiCrSiB}$ self-fluxing alloys play a crucial role in the time-dependent CE behaviour of metallic materials. Thus, in the case of multiphase materials, hardness cannot be the main indicator for CE prediction while it strongly depends on the initial material microstructure.

4. To qualitatively estimate the cavitation erosion damage $\left(\mathrm{CE}_{\mathrm{d}}\right)$ of a selected group of metallic materials (likewise $\mathrm{NiCrSiB}$ self-fluxing alloys) at specific test time, the factors likewise, material microstructure $(\mathrm{M})$; physical and mechanical properties $(\mathrm{P})$; and both surface morphology (S) and material loss (L) given at specific test time, can be combined in the following formula: $\mathrm{CE}_{\mathrm{d}}(t)=f(\mathrm{~S}, \mathrm{~L}, \mathrm{M}, \mathrm{P})$

Each of the factors included in a proposed relationship should be optimised and the formula must be validated for the broader range of selffluxing $\mathrm{NiCrSiB}$ deposits.

\section{REFERENCES}

1. Cruz J.R. da, Henke S.L., d'Oliveira A.S.C.M. Effect of Cold Work on Cavitation Resistance of an Austenitic Stainless Steel Coating. Materials Research. 2016; 19: 1033-1041. https://doi. org/10.1590/1980-5373-MR-2015-0442.

2. Nedeloni M.D., Birtărescu E., Nedeloni L., Ene T., Băra A., Clavac B. Cavitation Erosion and Dry Sliding Wear Research on X5CrNi18-10 Austenitic Stainless Steel. IOP Conf Ser: Mater Sci Eng. 2018; 416: 012028. https://doi.org/10.1088/1757899X/416/1/012028.

3. Szala M., Hejwowski T., Lenart I. Cavitation erosion resistance of $\mathrm{Ni}-\mathrm{Co}$ based coatings. Adv Sci Technol Res J. 2014; 8: 36-42. https://doi. org/10.12913/22998624.1091876.

4. Szala M., Łatka L., Awtoniuk M., Winnicki M., Michalak M. Neural Modelling of APS Thermal Spray Process Parameters for Optimizing the Hardness, Porosity and Cavitation Erosion Resistance of Al2O3-13 wt\% TiO2 Coatings. Processes. 2020; 8: 1544. https://doi.org/10.3390/pr8121544.

5. Singh J., Kumar S., Mohapatra S.K. An erosion and corrosion study on thermally sprayed WC-Co-Cr powder synergized with $\mathrm{Mo} 2 \mathrm{C} / \mathrm{Y} 2 \mathrm{O} 3 / \mathrm{ZrO} 2$ feedstock powders. Wear. 2019; 438-439. https://doi. org/10.1016/j.wear.2019.01.082.

6. Amarendra H.J., Chaudhari G.P., Nath S.K. Synergy of cavitation and slurry erosion in the slurry pot tester. Wear. 2012; 290-291: 25-31. https://doi. org/10.1016/j.wear.2012.05.025.

7. Hejwowski T., Szala M. Wear-Fatigue Study of Carbon Steels. Adv Sci Technol Res J. 2021; 15: 179190. https://doi.org/10.12913/22998624/140200.

8. Okada T., Iwai Y., Yamamoto A. A study of cavitation erosion of cast iron. Wear. 1983; 84: 297-312. https://doi.org/10.1016/0043-1648(83)90271-5.

9. Hattori S., Kitagawa T. Analysis of cavitation erosion resistance of cast iron and nonferrous metals based on database and comparison with carbon steel data. Wear. 2010; 269: 443-448. https://doi. org/10.1016/j.wear.2010.04.031.

10. Steller K. O mechanizmie niszczenia materiałów podczas kawitacji - On the mechanism of damage of materials during cavitation. Gdańsk, Poland: Institute of Fluid-Flow Machinery Polish Academy of Sciences; 1983.

11. Szala M., Chocyk D., Skic A., Kamiński M., Macek W., Turek M. Effect of Nitrogen Ion Implantation on the Cavitation Erosion Resistance and CobaltBased Solid Solution Phase Transformations of HIPed Stellite 6. Materials. 2021; 14: 2324. https:// doi.org/10.3390/ma14092324.

12. Roa C.V., Valdes J.A., Larrahondo F., Rodríguez 
S.A., Coronado J.J. Comparison of the Resistance to Cavitation Erosion and Slurry Erosion of Four Kinds of Surface Modification on 13-4 Ca6NM Hydro-Machinery Steel. J of Materi Eng and Perform. 2021; 30: 7195-7212. https://doi. org/10.1007/s11665-021-05908-9.

13. Stachowiak G., Batchelor A.W. Engineering Tribology. 4 edition. Butterworth-Heinemann; 2016.

14. Volkov-Husović T., Ivanić I., Kožuh S., Stevanović S., Vlahović M., Martinović S., et al. Microstructural and Cavitation Erosion Behavior of the $\mathrm{Cu}$ AlNi Shape Memory Alloy. Metals. 2021; 11: 997. https://doi.org/10.3390/met11070997.

15. Riemschneider E., Bordeasu I., Mitelea I., Utu I.D. Analysis of Cavitation Erosion Resistance of Grey Cast Iron EN-GJL-200 by the Surface Induction Hardening. IOP Conf Ser: Mater Sci Eng. 2018; 416: 012005. https://doi.org/10.1088/1757899X/416/1/012005.

16. Łatka L., Michalak M., Szala M., Walczak M., Sokołowski P., Ambroziak A. Influence of $13 \mathrm{wt} \%$ $\mathrm{TiO} 2$ content in alumina-titania powders on $\mathrm{mi}-$ crostructure, sliding wear and cavitation erosion resistance of APS sprayed coatings. Surface and Coatings Technology. 2021; 410: 126979. https:// doi.org/10.1016/j.surfcoat.2021.126979.

17. Czupryński A. Flame Spraying of Aluminum Coatings Reinforced with Particles of Carbonaceous Materials as an Alternative for Laser Cladding Technologies. Materials. 2019; 12: 3467. https:// doi.org/10.3390/ma12213467.

18. Gucwa M., Winczek J., Wieczorek P., Mičian M., Koňár R. The Analysis of Filler Material Effect on Properties of Excavator Crawler Track Shoe after Welding Regeneration. Archives of Metallurgy and Materials. 2021; 66: 31-36. https://doi. org/10.24425/amm.2021.134755.

19. Łatka L., Biskup P. Development in PTA Surface Modifications - A Review. Advances in Materials Science. 2020; 20: 39-53. https://doi.org/10.2478/ adms-2020-0009.

20. Tomków J., Świerczyńska A., Landowski M., Wolski A., Rogalski G. Bead-on-Plate Underwater Wet Welding on S700MC Steel. Adv Sci Technol Res J. 2021; 15: 288-296. https://doi. org/10.12913/22998624/140223.

21. Tomków J., Janeczek A. Underwater In Situ Local Heat Treatment by Additional Stitches for Improving the Weldability of Steel. Applied Sciences. 2020; 10: 1823. https://doi.org/10.3390/app10051823.

22. Janicki D. The friction and wear behaviour of insitu titanium carbide reinforced composite layers manufactured on ductile cast iron by laser surface alloying. Surface and Coatings Technology 2021; 406: 126634. https://doi.org/10.1016/j.surfcoat.2020.126634.
23. Munoz-Escalona P., Mridha S., Baker T.N. Advances in Surface Engineering Using TIG Processing to Incorporate Ceramic Particulates into Low Alloy and Microalloyed Steels - A Review. Adv Sci Technol Res J. 2021; 15: 88-98. https://doi. org/10.12913/22998624/138467.

24. Szala M., Świetlicki A., Sofińska-Chmiel W. Cavitation erosion of electrostatic spray polyester coatings with different surface finish. Bulletin of the Polish Academy of Sciences Technical Sciences 2021; 69: e137519. https://doi.org/10.24425/ bpasts.2021.137519.

25. Hibi M., Inaba K., Takahashi K., Kishimoto K., Hayabusa K. Effect of Tensile Stress on Cavitation Erosion and Damage of Polymer. J Phys: Conf Ser. 2015; 656: 012049. https://doi.org/10.1088/17426596/656/1/012049.

26. Zhou Y., Zhang J., Xing Z., Wang H., Lv Z. Microstructure and properties of $\mathrm{NiCrBSi}$ coating by plasma cladding on gray cast iron. Surface and Coatings Technology. 2019; 361: 270-279. https:// doi.org/10.1016/j.surfcoat.2018.12.055.

27. Mendez P.F., Barnes N., Bell K., Borle S.D., Gajapathi S.S., Guest S.D., et al. Welding processes for wear resistant overlays. Journal of Manufacturing Processes. 2014; 16: 4-25. https://doi. org/10.1016/j.jmapro.2013.06.011.

28. Jiménez H., Olaya J.J., Alfonso J.E. Tribological Behavior of Ni-Based WC-Co Coatings Deposited via Spray and Fuse Technique Varying the Oxygen Flow. Advances in Tribology. 2021; 2021: e8898349. https://doi.org/10.1155/2021/8898349.

29. Olejnik E., SzymańskiŁ., Batóg P., Tokarski T., Kurtyka P. TiC-FeCr local composite reinforcements obtained in situ in steel casting. Journal of Materials Processing Technology. 2020; 275: 116157. https://doi.org/10.1016/j.jmatprotec.2019.03.017.

30. Mikuš R., Kováč I., Žarnovský J. Effect of Microstructure on Properties of NiCrBSi Alloys Applied by Flame-Powder Deposition. Advanced Materials Research. 2014; 1059: 1-9. https://doi.org/10.4028/ www.scientific.net/AMR.1059.1.

31. Wang W., Li W., Xu H. Microstructures and Properties of Plasma Sprayed Ni Based Coatings Reinforced by TiN/C1-xNxTi Generated from In-Situ Solid-Gas Reaction. Materials. 2017; 10: 785. https://doi.org/10.3390/ma10070785.

32. Li W., Li J., Xu Y. Optimization of Corrosion Wear Resistance of the NiCrBSi Laser-Clad Coatings Fabricated on Ti6Al4V. Coatings. 2021; 11: 960. https://doi.org/10.3390/coatings11080960.

33. Kazamer N., Muntean R., Vălean P.C., Pascal D.T., Mărginean G., Șerban V.-A. Comparison of NiBased Self-Fluxing Remelted Coatings for Wear and Corrosion Applications. Materials. 2021; 14 : 3293. https://doi.org/10.3390/ma14123293. 
34. González R., Cadenas M., Fernández R., Cortizo J.L., Rodríguez E. Wear behaviour of flame sprayed NiCrBSi coating remelted by flame or by laser. Wear. 2007; 262: 301-307. https://doi. org/10.1016/j.wear.2006.05.009.

35. Miguel J.M., Guilemany J.M., Vizcaino S. Tribological study of NiCrBSi coating obtained by different processes. Tribology International. 2003; 36: 181-187. https://doi.org/10.1016/S0301-679X(02)00144-5.

36. Kekes D., Psyllaki P., Vardavoulias M., Vekinis G. Wear micro-mechanisms of composite WC-Co/CrNiCrFeBSiC coatings. Part II: Cavitation erosion. Tribology in Industry. 2014; 36: 375-383.

37. Zeng C., Tian W., Liao W.H., Hua L. Microstructure and porosity evaluation in laser-cladding deposited Ni-based coatings. Surface and Coatings Technology. 2016; 294: 122-130. https://doi.org/10.1016/j. surfcoat.2016.03.083.

38. Powder Welding. Surface Coating. Höganäs n.d. https://www.hoganas.com/en/powder-technologies/surface-coating/powder-welding/ (accessed October 14, 2021).

39. Nickel and Fe self-fluxing alloys for coatings n.d. http://www.polema-rus.com/eng-page/nickel-selffluxing-alloys-for-coatings.html (accessed October 4, 2021).

40. García A., Fernández M.R., Cuetos J.M., González R., Ortiz A., Cadenas M. Study of the Sliding Wear and Friction Behavior of $\mathrm{WC}+\mathrm{NiCrBSi}$ Laser Cladding Coatings as a Function of Actual Concentration of WC Reinforcement Particles in Ballon-Disk Test. Tribol Lett. 2016; 63:41. https://doi. org/10.1007/s11249-016-0734-3.

41. Dilawary S.A.A., Motallebzadeh A., Atar E., Cimenoglu H. Influence of Mo on the high temperature wear performance of NiCrBSi hardfacings. Tribology International. 2018; 127: 288-295. https://doi.org/10.1016/j.triboint.2018.06.022.

42. Cremer Beschichtungstechnologie $\mathrm{GmbH}, \mathrm{NiCrB}-$ Si n.d. https://cremer-coating.com/metal-spraying/ nicrbsi.html (accessed October 20, 2021).

43. Wang Y., Stella J., Darut G., Poirier T., Liao H., Planche M.-P. APS prepared NiCrBSi-YSZ composite coatings for protection against cavitation erosion. Journal of Alloys and Compounds. 2017; 699: 10951103. https://doi.org/10.1016/j.jallcom.2017.01.034.

44. Wu S.K., Lin H.C., Yeh C.H. A comparison of the cavitation erosion resistance of TiNi alloys, SUS304 stainless steel and Ni-based self-fluxing alloy. Wear. 2000; 244: 85-93. https://doi.org/10.1016/ S0043-1648(00)00443-9.

45. Szala M., Hejwowski T. Cavitation erosion resistance of coating flame deposited with nickel base powder. Przegląd spawalnictwa - Welding Technology Review. 2015; 87: 36-41.
46. ASTM G32-10: Standard Test Method for Cavitation Erosion Using Vibratory Apparatus. PA, USA: ASTM International: West Conshohocken, Philadelphia; 2010.

47. Hardfacing Powders. Kennametal Inc. Kennametal Inc 2019. https://www.stellite.com/us/en/products/ hardfacing-alloys/hardfacing-powders.html (accessed October 20, 2021).

48. Bergant Z., Grum J. Quality Improvement of Flame Sprayed, Heat Treated, and Remelted NiCrBSi Coatings. J Therm Spray Tech. 2009; 18: 380-391. https://doi.org/10.1007/s11666-009-9304-7.

49. Sawa M., Szala M., Henzler W. Innovative device for tensile strength testing of welded joints: 3d modelling, FEM simulation and experimental validation of test rig - a case study. Applied Computer Science. 2021; 17: 92-105. https://doi. org/10.23743/acs-2021-24.

50. Szala M., Szafran M., Macek W., Marchenko S., Hejwowski T. Abrasion Resistance of S235, S355, C45, AISI 304 and Hardox 500 Steels with Usage of Garnet, Corundum and Carborundum Abrasives. Adv Sci Technol Res J. 2019; 13: 151-161. https:// doi.org/10.12913/22998624/113244.

51. Szala M. Application of computer image analysis software for determining incubation period of cavitation erosion - preliminary results. ITM Web Conf 2017;15:06003. https://doi.org/10.1051/itmconf/20171506003.

52. Chmiel J., Jasionowski R., Zasada D. Cavitation erosion and corrosion of pearlitic gray cast iron in non-standardized cavitation conditions. Solid State Phenomena. 2015; 225: 19-24. https://doi. org/10.4028/www.scientific.net/SSP.225.19.

53. Kim B.-H., Kim B.-H., Koo Y.-H., Seo J.-H. A Study on the Cavitation Corrosion of Gray Cast Iron Liner by Antifreeze. Journal of the Korean Society of Manufacturing Process Engineers. 2017; 16: 7682. https://doi.org/10.14775/ksmpe.2017.16.4.076.

54. Tzanakis I., Bolzoni L., Eskin D.G., Hadfield M. Evaluation of Cavitation Erosion Behavior of Commercial Steel Grades Used in the Design of Fluid Machinery. Metall Mater Trans A. 2017; 48: 2193-2206. https://doi.org/10.1007/s11661017-4004-2.

55. Szala M., Łatka L., Walczak M., Winnicki M. Comparative Study on the Cavitation Erosion and Sliding Wear of Cold-Sprayed $\mathrm{Al} / \mathrm{Al} 2 \mathrm{O} 3$ and $\mathrm{Cu} /$ A12O3 Coatings, and Stainless Steel, Aluminium Alloy, Copper and Brass. Metals. 2020; 10: 856. https://doi.org/10.3390/met10070856.

56. Li Z.X., Zhang L.M., Ma A.L., Hu J.X., Zhang S., Daniel E.F., et al. Comparative study on the cavitation erosion behavior of two different rolling surfaces on 304 stainless steel. Tribology International 2021; 159: 106994. https://doi.org/10.1016/j. 
triboint.2021.106994.

57. Podulka P. Improved Procedures for Feature-Based Suppression of Surface Texture High-Frequency Measurement Errors in the Wear Analysis of Cylinder Liner Topographies. Metals. 2021; 11: 143. https://doi.org/10.3390/met11010143.

58. Zagórski I., Kulisz M., Kłonica M., Matuszak J. Trochoidal Milling and Neural Networks Simulation of Magnesium Alloys. Materials. 2019; 12: 2070. https://doi.org/10.3390/ma12132070.

59. Macek W., Branco R., Trembacz J., Costa J.D., Ferreira J.A.M., Capela C. Effect of multiaxial bending-torsion loading on fracture surface parameters in high-strength steels processed by conventional and additive manufacturing. Engineering Failure Analysis. 2020; 118: 104784. https://doi. org/10.1016/j.engfailanal.2020.104784.
60. Łatka L., Szala M., Michalak M., Pałka T. Impact of atmospheric plasma spray parameters on cavitation erosion resistance of $\mathrm{Al} 2 \mathrm{O} 3-13 \% \mathrm{TiO} 2$ coatings. Acta Phys Pol A. 2019; 136: 342-347. https:// doi.org/10.12693/APhysPolA.136.342.

61. Zakrzewska D.E., Krella A.K. Cavitation Erosion Resistance Influence of Material Properties. Advances in Materials Science. 2019; 19: 18-34. https://doi.org/10.2478/adms-2019-0019.

62. Hattori S., Ishikura R. Revision of cavitation erosion database and analysis of stainless steel data. Wear 2010; 268: 109-116. https://doi. org/10.1016/j.wear.2009.07.005.

63. Krella A.K. The new parameter to assess cavitation erosion resistance of hard PVD coatings. Engineering Failure Analysis. 2011; 18: 855-867. https:// doi.org/10.1016/j.engfailanal.2010.10.002. 